\title{
Time trends in incidence of peptic ulcer bleeding and associated risk factors in Norway 1985-2008
}

This article was published in the following Dove Press journal:

Clinical and Experimental Gastroenterology

25 June 2010

Number of times this article has been viewed

\section{Kåre E Bakkevold \\ Department of Surgery, Haugesund Hospital, Haugesund, Norway}

Objective: The aim of this study was to examine time trends in the incidence of peptic ulcer bleeding and risk factors in a defined geographical area in Norway.

Material and methods: Retrospective data were collected for 306 patients with bleeding peptic ulcers admitted to one hospital during the 1985-1986, 1995-1996, and 2007-2008 periods.

Results: The incidence in 1985-1986 was 52/100,000 and in 2007-2008 was 45/100,000. In the group aged $20-75$ years, the incidence decreased by $54 \%$ from $54 / 100000$ in $1985-1986$ to $25 / 100000$ in $2007-2008(P=0.001)$ and increased by $49 \%$ in the group aged $>75$ years from $272 / 100000$ to $406 / 100000(P=0.0001)$. The use of aspirin or nonsteroidal anti-inflammatory steroid drugs (NSAIDs) was $31 \%$ in $1985-1986$ and increased to $67 \%$ in $2007-2008(P=0.004)$. In patients using aspirin or NSAIDs, Helicobacter pylori was present in 73\% in 1995-1996 and in 51\% in 2007-2008. H. pylori infection declined from $84 \%$ to $52 \%$ between $1995-1996$ and 2007-2008.

Conclusions: The incidence rate of peptic ulcer bleeding did not change between 1985-1986 and 2007-2008, but decreased in the age group $\leq 75$ years and increased in the age group $>75$ years. The use of low-dose aspirin and NSAIDs increased substantially over time, and H. pylori infection was still present in $51 \%$ of these patients in 2007-2008.

Keywords: epidemiology, peptic ulcer bleeding, time trends, risk factors

\section{Introduction}

A bleeding gastroduodenal ulcer is a potentially life-threatening condition and may represent a major treatment challenge. The $\mathrm{H}_{2}$-receptor antagonists were introduced in Norway in the late 1970 for the treatment of peptic ulcer disease and were followed by the proton pump inhibitors (PPIs) in the late 1980s. Eradication regimens for Helicobacter pylori were introduced in south-western Norway in 1992. Effective medical treatment for peptic ulcer disease has therefore now been available in this area for almost 30 years, and a reduction in the incidence of bleeding peptic ulcers might be expected. Studies from the Netherlands ${ }^{1}$ and Germany ${ }^{2}$ show a stable incidence of ulcer bleeding when comparing the time periods 1993-1994 and 2000, and 1989-1990 and 1999-2000, respectively. In contrast, a report from Greece shows a 30\% decrease in the incidence of peptic ulcer bleeding from 1995 to $2005,{ }^{3}$ and another study from Italy shows a decrease of about 42\% from 1983-1985 to 2002-2004. ${ }^{4}$ Use of aspirin, NSAIDs, and the presence of $H$. pylori infection are recognized as important risk factors for ulcer bleeding. ${ }^{5-11}$ Oral corticosteroid use and current smoking are also reported as independent risk factors. ${ }^{12}$ There is a growing elderly population in Norway with an increased intake of low-dose aspirin and NSAIDs. The aim of this study was to
Correspondence: Kåre E Bakkevold Department of Surgery, Haugesund Hospital, Post Box 2170, N-5504 Haugesund, Norway

Tel + I I 474352732000

Fax + II 4743527324 II

Email kare.bakkevold@helse-fonna.no 
analyze time trends in the incidence of peptic ulcer bleeding between 1985 and 2008, and to elucidate the associated risk factors and symptoms prior to admission. The hypothesis was that there would be a time trend of decreased incidence of peptic ulcer bleeding in the population, especially in younger people due to treatment with $\mathrm{H}_{2}$-antagonists or PPIs, and/or eradication of $H$. pylori. In the elderly, more ulcer bleeding was expected due to a suggested increase in the use of aspirin or NSAIDs.

\section{Material and methods Inclusion and diagnosis}

Patients aged 20 years or older who had been emergency admissions to the surgical or medical department of Haugesund Hospital for acute gastrointestinal (GI) bleeding due to gastric or duodenal ulceration, with signs of serious bleeding such as melena and/or hematemesis, were included in the study. An upper GI endoscopy was performed for diagnosis on the day of admission or the next day in patients with stable circulation. Emergency endoscopy was performed during nights and weekends only in patients with unstable circulation and with signs and symptoms of very serious bleeding. To prevent exclusion of patients with bleeding ulcers from the study due to miscoding, ie, those not recorded as having a bleeding ulcer, the records of all patients with the diagnosis of duodenal or gastric ulcer were reviewed.

\section{Exclusion}

Patients with bleeding from malignant ulcers, or Dieulafoy's or Mallory-Weiss lesions were excluded. Endoscopic, surgical and laboratory data were retrospectively collected from the patients' case records and were stored anonymously using a specially designed computer program. Three two-year periods were studied, ie, 1985-1986 versus 2007-2008 and in addition 1995-1996, when testing and eradication of $H$. pylori was believed to have been established in this area after its introduction in Norway in 1992.

\section{Diagnostic tests for Helicobacter pylori}

Gastric biopsy for the detection of H. pylori was performed at the index endoscopy. If the test was negative or not performed due to massive bleeding, the intention was to repeat the test procedure at a second ambulatory endoscopy, without any treatment with $\mathrm{H}_{2}$-antagonists or PPIs in the previous 10 days, to exclude a false-negative test at the index endoscopy. Both a positive urease rapid test within 24 hours and histologic verification were required for diagnosis of H. pylori infection.

\section{Hospital catchment population}

Every patient with acute GI bleeding in the hospital catchment area was admitted to Haugesund Hospital in 1985-1986 and 2007-2008. The hospital catchment area did not change during this time. The total population in the catchment area had increased from 96,674 inhabitants in 1985-1986 to 109,240 in 2007-2008. The total population and its age distribution for the three study time periods were obtained from the Norwegian official statistics published on the Internet. ${ }^{13}$ The total annual incidence rates were calculated by using the mean number of patients with bleeding peptic ulcer versus the mean population in each two-year period. Two age groups, the first being 20-75 years and the second being older than 75 years, were selected to identify any differences according to age. Age-related incidence rates were calculated in parallel with the total incidence rates. Every registered patient was assumed to be under observation for one year in each study period. The rates were expressed per 100,000 person-years of observation. Risk factors and other variables were compared by $\chi^{2}$-test or Fisher's exact test when appropriate. The recording of data and the calculations were performed with the Statistica program package (Statsoft Inc., Tulsa, OK).

\section{Results \\ Incidence}

In total, 306 patients with bleeding duodenal or gastric ulcer were included during the three two-year study periods from January 1, 1985 to December 31, 2008. Incidence rates for all patients and for the two age groups are shown in Table 1. The total incidence rate of peptic ulcer bleeding in the population did not differ significantly between the three time periods. In the age group 20-75 years, the incidence rate decreased by $54 \%$ between $1985-1986$ and $2007-2008(P=0.001)$. In those patients older than 75 years, the incidence increased by $49 \%$ from the earliest to the last study time period $(P=0.0001)$. Demographic details of the patients, their previous history of peptic ulcer disease, dyspepsia, and hematemesis prior to admission for a bleeding ulcer are given in Table 2. The number of patients complaining of dyspepsia prior to ulcer bleeding decreased by $80 \%$ between $1985-1986$ and 2007-2008 $(P=0.0000)$.

\section{Risk factors for bleeding Aspirin and NSAIDs}

Use of drugs recognized as causing ulcers or known to contribute to bleeding and the results of $H$. pylori testing are shown in Table 3 . Findings at the index endoscopy 
Table I Number of patients/population (incidence ${ }^{a}$ ) and age-adjusted incidence of peptic ulcer bleeding in a defined geographical area in Norway during the time periods 1985-1986, 1995-1996, and 2007-2008

\begin{tabular}{|c|c|c|c|c|}
\hline Time period & | 985-1986 & 1995-1996 & 2007-2008 & $P$ value \\
\hline \multicolumn{5}{|l|}{ Age (years) } \\
\hline$\geq 20 \leq 75$ & $66 / 60726(54)^{\prime}$ & $69 / 63384(54)$ & $36 / 71096(25)^{2}$ & 0.00 I (I vs 2 ) \\
\hline$<75$ & $33 / 6060(272)^{\prime}$ & $39 / 6503(300)$ & $63 / 7754(406)^{2}$ & 0.000 I (I vs 2) \\
\hline Total & $101^{b} / 96674(52)^{a}$ & 108/99294 (54) & $99 / 109240(45)$ & NS \\
\hline
\end{tabular}

Notes: acases/100,000/year; btwo patients younger than 20 years ( 16 and 18 years) were included in 1985-1986.

Abbreviation: NS, not significant.

related to use or nonuse of aspirin and NSAID, ulcer size, and bleeding activity according to time period are shown in Table 4. The ratio between duodenal and gastric ulcers $(\mathrm{Du} / \mathrm{Gu})$ was comparable between the time periods. The $\mathrm{Du} /$ Gu ratio was twice as high in nonusers of aspirin or NSAIDs compared with users of these agents. The use of high- or low-dose aspirin or NSAIDs increased by $116 \%$ between $1985-1986$ and $2007-2008(P=0.004)$ and by $72 \%$ between 1995-1996 and 2007-2008 $(P=0.03)$. In patients aged 25-75 years, use of aspirin or NSAIDs increased by $103 \%$ between 1985-1986 and 2007-2008 $(P=0.06)$. In patients aged 75 years or older, use of aspirin or NSAIDs increased by $112 \%$ between $1985-1986$ and $2007-2008(P=0.06)$. In 2007-2008 aspirin was coprescribed in addition to an NSAID in $14 / 37$ (38\%) patients, warfarin in 5/37 (14\%), and steroids in 6/37 (16\%), respectively. Nine of $32(28 \%)$ of patients with a prior history of peptic ulcer disease used low-dose aspirin or NSAIDs in 2007-2008.

\section{Tobacco and alcohol}

Tobacco and alcohol use did not differ significantly when the three time periods were compared. Numbers of smokers and alcohol intake were small, although the information provided by patients on these issues may have been incorrect. The amount of alcohol intake was not recorded, but all patients included in this group had a period of heavy drinking prior to admission.

\section{Other drugs}

No patients were identified to have used clopidogrel as a single antiplatelet drug. A few patients in 2007-2008 may have used clopidogrel in addition to aspirin, but this was not recorded during the study. Concomitant intake of a PPI or $\mathrm{H}_{2}$-antagonist was not used by any patient at admission during any of the study time periods.

\section{Helicobacter pylori}

The result of $H$. pylori testing are shown in Table 3. In 1995-1996, 84\% of the tested patients were positive for $H$. pylori versus $52 \%$ in $2007-2008(P=0.06)$. In $1995-1996$ and in 2007-2008 H. pylori was confirmed in $73 \%$ and $51 \%$ of patients using aspirin or NSAIDs, respectively. In nonusers of aspirin or NSAIDs, $89 \%$ had a positive $H$. pylori test in 1995-1996 and 55\% in 2007-2008. In 2007-2008, 10\% of the patients were $H$. pylori negative and nonusers of low-dose aspirin or NSAIDs.

\section{Discussion}

\section{Incidence}

The overall incidence of bleeding peptic ulcers in this study did not change from 1985-1986 (52/100000) to 2007-2008 (46/100000) which is consistent with reports from Northern Europe ${ }^{1,2}$ but in contrast with reports from Greece and Italy., Penston et $\mathrm{al}^{5}$ reported a decrease in the incidence of peptic ulcer bleeding of 29\% between 1981-1985 and 1986-1990

Table 2 Demographics, ulcer history, dyspepsia and hematemesis in patients admitted for peptic ulcer bleeding in the time periods 1985-1986, 1995-1996, and 2007-2008

\begin{tabular}{|c|c|c|c|c|}
\hline & $1985-1986$ & $1995-1996$ & 2007-2008 & $P$ value \\
\hline Patients (n) & 99 & 108 & 99 & \\
\hline Male/female & $49 / 50$ & $67 / 41$ & $54 / 45$ & NS \\
\hline Mean age $(95 \% \mathrm{Cl})$ & $63(59-66)$ & $69(65-73)$ & $74(70-78)$ & \\
\hline Previous ulcer & $47(47)$ & $44(4 I)$ & $32(32)$ & NS \\
\hline Previous bleeding ulcer & $25(25)$ & $16(15)$ & $13(13)$ & NS \\
\hline Previous perforated ulcer & $4(4)$ & I $(0.9)$ & $3(3)$ & NS \\
\hline Dyspepsia & $59(60)^{a}$ & $48(44)^{b}$ & $12(12)^{c}$ & $\begin{array}{l}0.0000-0.0002 \\
\text { (a, b, vs c) }\end{array}$ \\
\hline Hematemesis & $42(42)$ & $44(4 I)$ & $39(39)$ & NS \\
\hline
\end{tabular}

Abbreviations: $\mathrm{Cl}$, confidence interval; NS, not significant. 
Table 3 Oral use of aspirin or NSAIDs, drugs which may be related to bleeding, alcohol, tobacco, and Helicobacter pylori

\begin{tabular}{|c|c|c|c|c|}
\hline & $1985-1986$ & $1995-1996$ & 2007-2008 & $P$ value \\
\hline & $n=99$ & $n=108$ & $n=99$ & \\
\hline High-dose aspirin' & $18(18)^{a}$ & $8(7)^{b}$ & $I(I)^{c}$ & $0.000 \mathrm{I}$ (a vs c) \\
\hline Low-dose aspirin ${ }^{2}$ & $\mathrm{I}(\mathrm{I})^{\mathrm{a}}$ & $12(\mathrm{II})^{\mathrm{b}}$ & $37(37)^{c}$ & $0.007-0.0000$ \\
\hline $\mathrm{NSAIDs}^{3}$ & $12(12)^{\mathrm{a}}$ & $24(22)^{b}$ & $42(42)^{c}$ & $0.03-0.0003(a, b, v s c)$ \\
\hline Aspirin or NSAIDs & $31(31)^{a}$ & $42(39)^{b}$ & $66(67)^{c}$ & $0.004-0.03$ (a, b, vs c) \\
\hline \multicolumn{5}{|l|}{ Aspirin or NSAIDs } \\
\hline 20-75years & $20 / 66(30)^{\mathrm{a}}$ & $22 / 69(32)^{b}$ & $22 / 36(6 I)^{c}$ & 0.06 (a vs c) \\
\hline$>75$ years & $11 / 33(33)^{\mathrm{a}}$ & $20 / 39(5 \mathrm{I})^{\mathrm{b}}$ & $44 / 63(70)^{c}$ & 0.06 (a vs c) \\
\hline Warfarin & $0^{\mathrm{a}}$ & $4(4)^{b}$ & $18(18)^{c}$ & $0.0000-0.002$ (a, b vs $c)$ \\
\hline Steroids & $\mathrm{I}(\mathrm{I})^{\mathrm{a}}$ & $9(8)^{b}$ & $12(12)^{c}$ & $0.02-0.003(\mathrm{a}$ vs b, c) \\
\hline Alcohol & $8(8)$ & $6(6)$ & $7(7)$ & NS \\
\hline Tobacco & $27(27)$ & $21(19)$ & $15(15)$ & NS \\
\hline H. pylori tested & & $87(8 I)$ & $75(76)$ & NS \\
\hline H. pylori positive & & $73(84)$ & $39(52)$ & 0.06 \\
\hline \multicolumn{5}{|l|}{ H. pylori positive } \\
\hline Duodenal ulcer & & $51 / 62(82)$ & $27 / 47(57)$ & NS \\
\hline Gastric ulcer & & $22 / 25(88)$ & $12 / 28(43)$ & NS \\
\hline \multicolumn{5}{|l|}{ H. pylori positive } \\
\hline Aspirin or NSAID users & & $22 / 30(73)$ & $28 / 55(5 I)$ & NS \\
\hline Nonusers & & $5 \mathrm{I} / 57(89)$ & $1 \mathrm{l} / 20(55)$ & NS \\
\hline
\end{tabular}

Notes: 'Aspirin 0.5-Ig; ${ }^{2}$ Aspirin 75-160 mg; 1,2,3Patients with simultaneous use of aspirin and NSAID are recorded twice.

Abbreviations: NS, not significant; NSAID, nonsteroidal anti-inflammatory drug.

in the community of Tayside in Scotland versus unchanged rates in Scotland overall, which was attributed to long-term $\mathrm{H}_{2}$-receptor antagonist treatment of peptic ulcer patients in Tayside. Long-term continuous treatment of peptic ulcer disease with $\mathrm{H}_{2}$-receptor antagonists or PPIs has not been used to any extent in the area studied in Norway, but is unlikely to explain the unchanged incidence rate. Loperfido et $\mathrm{al}^{4}$ reported that the decline in the incidence rate of ulcer bleeding only occurred in people younger than 70 years of age, which is consistent with the results of our present study, but the increased incidence in patients older than 75 years would account for the unchanged rate in this Norwegian population. No change in the number of patients with bleeding ulcers was reported from Australia between 1997 and 2007, and the patients

Table 4 Findings at the index endoscopy related to oral use or nonuse of aspirin or NSAIDs

\begin{tabular}{|c|c|c|c|c|}
\hline & $1985-1986$ & $1995-1996$ & 2007-2008 & $P$ value \\
\hline & $n=99$ & $n=108$ & $n=99$ & \\
\hline Duodenal ulcer & $52(53)$ & $72(67)$ & $58(59)$ & \\
\hline Gastric ulcer & $47(47)$ & $36(33)$ & $4 I(4 I)$ & \\
\hline DU/GU ratio & 1.1 & 2 & 1.4 & NS \\
\hline \multicolumn{5}{|l|}{ Aspirin or NSAID users } \\
\hline Duodenal ulcer & $12(23)^{a}$ & $24(33)^{b}$ & $36(62)^{c}$ & $0.01-0.06$ (a, b vs c) \\
\hline Gastric ulcer & $19(40)$ & $18(50)$ & $30(73)$ & NS \\
\hline DU/GU ratio (users) & 0.6 & 1.3 & 1.2 & \\
\hline \multicolumn{5}{|l|}{ Aspirin or NSAID nonusers } \\
\hline Duodenal ulcer & $40(77)^{\mathrm{a}}$ & $48(67)^{b}$ & $22(38)^{c}$ & $0.03-0.07$ (a, b vs c) \\
\hline Gastric ulcer & $28(60)^{a}$ & $18(50)^{b}$ & II (27) & 0.07 (a vs c) \\
\hline DU/GU ratio (nonusers) & 1.4 & 2.7 & 2 & \\
\hline Ulcer size $>2 \mathrm{~cm}$ & $23(23)$ & $30(28)$ & $23(23)$ & NS \\
\hline \multicolumn{5}{|l|}{ Bleeding activity (Forrest) } \\
\hline Arterial $(\mathrm{F} \mathrm{la})$ & $4(4)$ & $5(5)$ & $5(5)$ & NS \\
\hline Oozing (F Ib) & $15(15)$ & $10(9)$ & $18(18)$ & NS \\
\hline Visible vessel (F 2a) & $2(2)$ & $3(3)$ & $7(7)$ & NS \\
\hline Clot (F 2b) & $9(9)$ & $5(4)^{b}$ & $16(16)^{c}$ & 0.02 (b vs c) \\
\hline Black spot (F 2c) & $2(2)^{a}$ & $14(13)^{b}$ & $26(26)^{c}$ & $0.007-0.0000(\mathrm{a}$ vs b, c) \\
\hline No signs (F 3) & $67(68)^{a}$ & $71(66)^{b}$ & $27(27)^{c}$ & $0.0006-0.0008$ (a, b vs c) \\
\hline
\end{tabular}

Abbreviations: DU, duodenal ulcer; GU, gastric ulcer; NSAID, nonsteroidal anti-inflammatory drug. 
studied were also significantly older. ${ }^{14}$ This is consistent with the results of our study. In contrast, a population-based study by Lanas et $\mathrm{al}^{15}$ involving 10 hospitals in Spain reported a clear decreasing trend in upper GI admissions between 1996 and 2005. This trend is consistent with other reports from southern Europe. ${ }^{3,4}$ The use of NSAIDs increased in the three studies from southern Europe, ${ }^{3,4,15}$ as was found in the present study. The different time trends in overall incidence rates between these studies ${ }^{3,4,15}$ and the present study may reflect a higher prescription rate of $\mathrm{H}_{2}$-antagonists, PPIs, or $\mathrm{H}$. pylori eradication regimens in the populations in these countries than in the region of Norway studied here.

\section{Aspirin and NSAIDs}

In the present study the increased use of aspirin or NSAIDs between 1985-1986 and 2007-2008, especially in the older patients, may be a major contributor to the increased incidence of ulcer bleeding in those older than 75 years. Comorbidity and interactions with other drugs which increase the risk for bleeding eg, clopidogrel, may also contribute, reportedly up to $45 \% .^{12}$ However, the use of aspirin or NSAIDs also increased in the younger age group between 1985-86 and 2007-2008. The decline in the incidence of peptic ulcer bleeding in people younger than 75 years may be the result of a combination of favorable factors, eg, eradication of $H$. pylori, short-term treatment with $\mathrm{H}_{2}$-antagonists or PPIs, or a beneficial change in lifestyle factors in this age group. In 2007-2008, 67\% of the bleeding ulcers were attributed to or associated with aspirin or NSAIDs in this study, whereas other studies have reported rates of $46 \%-80 \%$. ${ }^{1,3,4,12,14}$

\section{Gastric/duodenal ulcer ratio}

An increased $\mathrm{Gu} / \mathrm{Du}$ ratio was expected when comparing the earlier and later time periods due to the increased use of aspirin or NSAIDs. This ratio did not change in accordance with the report by Ohmann et al. ${ }^{2}$ This may be explained by the low numbers of patients in each study period (Type II error). However, when users of aspirin or NSAIDs versus nonusers were compared, the ratio was about twice as high in each time period. The oral anticoagulant warfarin and low-dose aspirin were also coprescribed in the present study in 2007-2008 which would increase the risk of serious ulcer bleeding. ${ }^{16}$

\section{Dyspepsia}

Dyspepsia prior to hospital admission decreased from $60 \%$ to $12 \%$ between $1985-1986$ and $2007-2008(P=0.0000)$. Dyspepsia is a major symptom in chronic peptic ulcer disease, and the increased frequency of patients without dyspeptic complaint prior to an ulcer bleeding is consistent with the findings of Gururatsakul et al and Henriksson et al. ${ }^{14,18}$ This change in symptom suggests an increased ratio of acute versus chronic ulcers caused by increased use of low-dose aspirin or NSAIDs.

\section{Helicobacter pylori}

The prevalence of $H$. pylori infection declined between 1995-1996 and 2007-2008. The previously reported prevalence of $H$. pylori infection in 1998-1999 of about $75 \%-80 \%{ }^{17-19}$ is comparable with the prevalence seen in the present study in 1995-1996. The decline in prevalence of H. pylori infection in patients with bleeding ulcers between 1995-1996 and 2007-2008 $(P=0.06)$, and also in nonusers of aspirin or NSAIDs, may be due to eradication of $H$. pylori in patients with uncomplicated peptic ulcer disease. The sensitivity of rapid urease testing and histology to detect H. pylori infection have been reported to be 0.67 and 0.70 , respectively. ${ }^{20}$ The sensitivity of these two tests is assumed to have been similar in 1995-1996 and 2007-2008 in the present study. This may suggest a real decrease in $H$. pylori infection in patients with bleeding ulcers between 1995-1996 and 2007-2008. The low proportion of patients tested for $H$. pylori especially in 2007-2008 creates a bias in the interpretation of this time trend for $H$. pylori infection. The low percentage of patients tested presumably reflects ongoing treatment with PPIs, both at the index and at a second endoscopy where the ulcer may have been healed.

\section{Helicobacter pylori, aspirin, NSAIDs}

The combination of $H$. pylori infection and other risk factors, such as aspirin or NSAIDs, was high in the present study, being 73\% and 51\% in 1995-1996 and 2007-2008, respectively. These three risk factors had an impact on the etiology of $90 \%$ of bleeding peptic ulcers in the 2007-2008 study period. A study at Beograd ${ }^{21}$ identified that about $20 \%$ of patients with bleeding ulcers had none of these three risk factors, while Gisbert et $\mathrm{al}^{22}$ found that only $2 \%$ of patients developed bleeding ulcers in the absence of these risk factors. A study from $\operatorname{Japan}^{23}$ reported a corresponding prevalence of $11 \%$, which is comparable with that in the present study. H. pylori, aspirin, and NSAIDs represent independent and synergistic risk factors both for uncomplicated peptic ulcer disease and for bleeding ulcers. ${ }^{23-26}$ Eradication of $H$. pylori is recommended before NSAID therapy to reduce the risk for peptic ulcer disease. ${ }^{27,28}$ Eradication is also recommended before the start of low-dose aspirin prophylaxis. ${ }^{29-31}$ The results of the present study support both these recommendations. 
A limitation of this study is its retrospective design which may have introduced bias, eg, from absent data on previous ulcer disease, dyspepsia, oral use of other drugs which may induce or contribute to bleeding, anti-ulcer drugs, and use of tobacco and alcohol. To achieve the most reliable data, especially regarding the use of ulcerogenic drugs and other drugs which may contribute to bleeding, data were recorded from records at hospital admission, from previous hospitalizations, and supplied or corrected with data recorded during the hospital stay and eventually at an ambulatory endoscopy after discharge from hospital. Estimation of ulcer size and classification of bleeding activity may be inaccurate due to the variable time lag between admission and the index endoscopy, as well as observer variation between endoscopists. Significant differences in findings for bleeding activity between the three time periods, ie, clot, black spot, and no signs (Table 4), need to be validated in future prospective studies. The low number of patients in each time period, especially for interpreting the results according to the two age groups, gives a low power in the statistical analyses and an increased likelihood of Type II error.

\section{Conclusion}

The overall incidence of bleeding peptic ulcers between 1985-1986 and 2007-2008 remained unchanged in the population in this area of Norway. However, the incidence decreased by 54\% in the age group 20-75 years and increased by $49 \%$ in those older than 75 years. The use of aspirin or NSAIDs prior to an ulcer bleeding increased from $31 \%$ to 67\% between 1985-1986 and 2007-2008. In 2007-2008, only $10 \%$ of the patients with peptic ulcer bleeding were nonusers of low-dose aspirin or NSAIDs and H. pylori negative. Dyspepsia prior to an emergency hospital admission for peptic ulcer bleeding declined from $60 \%$ to $12 \%$ in the same time period, which suggests an increasing frequency of acute bleeding ulcers caused by the use of ulcerogenic drugs.

\section{Disclosure}

The author has no financial or other personal interest in this study and has not received financial support from any source.

\section{References}

1. van Leerdam ME, Vreeburg EM, Rauws EA, et al. Acute upper GI bleeding: Did anything change? Time trend analysis of incidence and outcome of acute upper GI bleeding between 1993/1994 and 2000. Am J Gastroenterol. 2003;98:1494-1499.

2. Ohmann C, Imhof M, Ruppert C, et al. Time trends in the epidemiology of peptic ulcer bleeding. Scand J Gastroenterol. 2005;40:914-920.
3. Theocharis GJ, Thomopoulos KC, Sakellaropoulos G, et al. Changing trends in the epidemiology and clinical outcome of acute upper gastrointestinal bleeding in a defined geographical area in Greece. J Clin Gastroenterol. 2008;42:128-133.

4. Loperfido S, Baldo V, Piovesana E, et al. Changing trends in acute upper GI bleeding: A population based study. Gastrointest Endosc. 2009;70(2):212-224.

5. Penston JG, Crombie IK, Waugh NR, et al. Trends in morbidity and mortality from peptic ulcer disease: Tayside versus Scotland. Aliment Pharmacol Ther. 1993;7:429-442.

6. Hawkey CJ. Non-steroidal anti-inflammatory drugs and peptic ulcers. Br Med J. 1990;300:278-284.

7. Thomsen RW, Riis A, Christensen S, et al. Outcome of peptic ulcer bleeding among users of traditional non-steroidal anti-inflammatory drugs and selective cyclo-oxygenase-2 inhibitors. Aliment Pharmacol Ther. 2006;24:1431-1438.

8. Serrano P, Lanas A, Arroyo MT, et al. Risk of upper gastrointestinal bleeding in patients taking low-dose aspirin for the prevention of cardiovascular diseases. Aliment Pharmacol Ther. 2002;16: 1945-1953.

9. Ishikawa S, Inaba T, Mizumo M, et al. Incidence of serious upper gastrointestinal bleeding in patients taking non-steroidal anti-inflammatory drugs in Japan. Acta Med Okayama. 2008;62:29-36.

10. Nakayama M, Iwakiri R, Hara M, et al. Low-dose aspirin is a prominent cause of bleeding ulcers in patients who underwent emergency endoscopy. J Gastroenterol. 2009;44(9):912-918.

11. Matikainen M, Kangas E. Is there a relationship between the use of analgesics and non-steroidal anti-inflammatory drugs and acute upper gastrointestinal bleeding? A Finnish case-control prospective study. Scand J Gastroenterol. 1996;31:912-916.

12. Weil J, Langman MJ, Wainwright P, et al. Peptic ulcer bleeding: Accessory risk factors and interactions with non-steroidal anti-inflammatory drugs. Gut. 2000;46:27-31.

13. Statistics Norway. Available from: http://www.ssb.no/befolkning-en/. Accessed on March 10, 2010

14. Gururatsakul M, Ching KJ, Talley NJ, et al. Incidence and risk factors of uncomplicated peptic ulcer and bleeding peptic ulcer over a 10-year period. Gastrointest Endosc. 2009;69:AB 607.

15. Lanas A, García-Rodríguez LA, Polo-Tomás M, et al. Time trends and impact of upper and lower gastrointestinal bleeding and perforation in clinical practice. Am J Gastroenterol. 2009;104:1633-1641.

16. Younossi ZM, Strum WB, Schatz RA, et al. Effect of combined anticoagulation and low-dose aspirin treatment on upper gastrointestinal bleeding. Dig Dis Sci. 1997;42:79-82.

17. Kuyvenhoven JPh, Veenendaal RA, Vandenbroucke JP. Peptic ulcer bleeding: Interaction between non-steroidal anti-inflammatory drugs, Helicobacter pylori infection, and the ABO blood group system. Scand J Gastroenterol. 1999;34:1082-1086.

18. Henriksson AE, Edman AC, Nilsson I, et al. Helicobacter pylori and the relation to other risk factors in patients with acute bleeding peptic ulcer. Scand J Gastroenterol. 1998;33:1030-1033.

19. Gisbert JP, Calvet X. Review article: Helicobacter pylori-negative duodenal ulcer disease. Aliment Pharmacol Ther. 2009;30: 791-815.

20. Gisbert JP, Abraira V. Accuracy of Helicobacter pylori diagnostic tests in patients with bleeding peptic ulcer: A systematic review and metaanalysis. Am J Gastroenterol. 2006;101:848-863.

21. Sokić-Milutinović A, Krstić M, Popović D, et al. Role of Helicobacter pylori infection and use of NSAIDS in the etiopathogenesis of upper gastrointestinal bleeding. Acta Chir Iugosl. 2007;54:51-62. Serbian.

22. Gisbert JP, Gonzalez L, de Pedro A, et al. Helicobacter pylori and bleeding duodenal ulcer: Prevalence of the infection and role of nonsteroidal anti-inflammatory drugs. Scand J Gastroenterol. 2001;36: 717-724.

23. Ootani H, Iwakiri R, Shimoda R, et al. Role of helicobacter pylori infection and nonsteroidal anti-inflammatory drug use in bleeding peptic ulcers in Japan. J Gastroenterol. 2006;41:41-46. 
24. Papatheodoridis GV, Songioultzis S, Archimandritis AJ. Effects of helicobacter pylori and nonsteroidal anti-inflammatory drugs on peptic ulcer disease: A systematic review. Clin Gastroenterol Hepatol. 2006;4:130-142.

25. Huang JQ, Sridhar S, Hunt RH. Role of helicobacter pylori infection and non-steroidal anti-inflammatory drugs in peptic ulcer disease: A metaanalysis. Lancet. 2002;359:14-22.

26. Lanas A, Fuentes J, Benito R, et al. Helicobacter pylori increases the risk of upper gastrointestinal bleeding in patients taking low-dose aspirin. Aliment Pharmacol Ther. 2002;16:779-786.

27. Chan FK, Sung JJ, Chung SC, et al. Randomised trial of eradication of Helicobacter pylori before non-steroidal anti-inflammatory drug therapy to prevent peptic ulcers. Lancet. 1997;350:975-979.

28. Leung WK, To KF, Chan FK, et al. Interaction of Helicobacter pylori eradication and non-steroidal anti-inflammatory drugs on gastric epithelial apoptosis and proliferation: Implications on ulcerogenesis. Aliment Pharmacol Ther. 2000;14:879-885.
29. Lanas A, Scheiman J. Low-dose aspirin and upper gastrointestinal damage: Epidemiology, prevention and treatment. Curr Med Res Opin. 2007; 23:163-173.

30. Chan FK. Should we eradicate Helicobacter pylori infection in patients receiving nonsteroidal anti-inflammatory drugs or low-dose aspirin? Chin J Dig Dis. 2005;6:1-5.

31. Chan FK, Chung SC, Suen By, et al. Preventing recurrent upper gastrointestinal bleeding in patients with Helicobacter pylori infection who are taking low-dose aspirin or naproxen. $N$ Engl J Med. 2001; 344:967-973.
Clinical and Experimental Gastroenterology

\section{Publish your work in this journal}

Clinical and Experimental Gastroenterology is an international, peerreviewed, open access journal, publishing all aspects of gastroenterology in the clinic and laboratory, including: Pathology, pathophysiology of gastrointestinal disease; Investigation and treatment of gastointes tinal disease; Pharmacology of drugs used in the alimentary tract;

\section{Dovepress}

Immunology/genetics/genomics related to gastrointestinal disease. This journal is indexed on CAS. The manuscript management system is completely online and includes a very quick and fair peer-review system. Visit http://www.dovepress.com/testimonials.php to read real quotes from published authors.

Submit your manuscript here: http://www.dovepress.com/clinical-and-experimental-gastroenterology-journal 